\title{
Thallium-20I exercise myocardial imaging to evaluate myocardial perfusion after coronary artery bypass surgery*
}

\author{
HEINZ O HIRZEL, KARL NUESCH, GREGORIO SIALER, WOLFGANG HORST, \\ HANS P KRAYENBUEHL
}

\begin{abstract}
From the Division of Cardiology, Medical Policlinic, Department of Internal Medicine, and the Clinic of Nuclear Medicine, University Hospital, Zurich, Switzerland
\end{abstract}

SUMMARY To assess the usefulness of thallium-201 exercise scintigraphy in evaluating myocardial perfusion after coronary artery bypass surgery imaging was performed after submaximal bicycle ergometry and at rest in 54 patients before and within $24 \pm 10$ (SD) weeks after operation. According to the postoperative scintigram the patients were assigned to three groups. Group 1 comprised 31 patients whose perfusion returned to normal after exercise and at rest within the preoperatively ischaemic regions; group 2 comprised 16 patients with identical pre- and postoperative exercise-induced perfusion defects, and group 3 comprised seven patients with enlarged or new perfusion defects postoperatively.

Clinically, 14 of 31 patients in group 1 were symptom free after operation, two of whom, however, showed an abnormal exercise electrocardiogram; whereas the other 17 patients still complained of chest pain and in six of them the exercise electrocardiogram was also pathological. In group 2 eight of 16 patients were symptom free after operation and showed normal exercise electrocardiograms and the other eight continued to suffer from angina, and seven had a pathological exercise electrocardiogram. All seven patients in group 3 were symptomatic and showed an abnormal exercise electrocardiogram. Thus, scintigraphy identified eight of 20 patients $(40 \%)$ who were symptom free and showed normal exercise electrocardiograms as still having exercise-induced ischaemia and thus as having not truly benefited from the surgical intervention. In contrast, improvement in perfusion was documented in 17 of 31 patients $(53 \%)$ despite further complaints of chest pain and persistence of a pathological exercise electrocardiogram in six of them.

Bypass graft patency rate paralleled the scintigraphic findings in the 35 patients who were restudied arteriographically. In group 1 (16 patients restudied) the graft patency rate was 81 per cent, significantly different from the 38 per cent in group 2 (13 patients restudied), and it was only 15 per cent in group 3 (six patients restudied). Similarly, the degree of vascular obstruction had decreased in group 1 from a score of $2 \cdot 1 \pm 0.3(\mathrm{SEM})$ preoperatively to a score of $1 \cdot 1 \pm 0.3$ postoperatively, remained unchanged in group 2 , averaging $3.0 \pm 0.4$ score values preoperatively and $3.1 \pm 0.5$ score values postoperatively, and even tended to increase in group 3 from $2.2 \pm 0.6$ score values preoperatively to $3.3 \pm$ 0.6 score values postoperatively.

It is concluded that thallium-201 exercise scintigraphy is a useful technique to document changes in regional perfusion after surgery and is definitely superior to the clinical evaluation of patients including the exercise electrocardiogram.

More than 10 years have elapsed since coronary artery bypass surgery was introduced into the *This work was supported partly by a grant of the Fritz Hoffmann-La Roche Foundation for Medical Research.

Presented in part at the First Joint Meeting of the Working Groups of the European Society of Cardiology, Brighton, UK, 1978. Received for publication 29 August 1979 management of coronary heart disease as a new therapeutic principle. Because of the low operative mortality and the high incidence of symptomatic improvement, the technique has recently become one of the most popular surgical procedures in the United States and Western Europe. ${ }^{1-3}$ Relief of 
pain is generally attributed to successful revascularisation and usually correlates with graft patency. Several patients, however, have benefited symptomatically despite angiographically verified graft closure. ${ }^{4-6}$ Moreover, with regard to angina pectoris perioperative myocardial infarction could conceal unsuccessful coronary revascularisation. ${ }^{7}$ On the other hand, there are patients with patent grafts who describe postoperative chest pain often indistinguishable from true ischaemic angina.

Since the success or the failure of surgical revascularisation is not always apparent clinically or from routine laboratory tests such as the exercise electrocardiogram and the determination of the physical working capacity, other techniques which provide a more specific picture of the postoperative status of vascularisation are needed. The morphological proof of bypass graft patency requires cardiac catheterisation, but as this is invasive it is not suitable as a routine method or for regular examinations.

Myocardial perfusion scintigraphy with potassium- 43 and rubidium- 81 has been shown to be useful for evaluating the result of coronary artery bypass surgery. ${ }^{910}$ Because of superior physical and biological properties thallium-201 is even more appropriate and has therefore become the most widely used radionuclide imaging agent. Even though thallium-201 exercise myocardial imaging has already been used in several studies for the postoperative analysis of myocardial perfusion, the arguments presented to date are not fully convincing. Whereas Degeorges et al. ${ }^{11}$ from experience with three patients were enthusiastic about the usefulness of scintigraphy, Rosenblatt and his colleagues stated ${ }^{12}$ that, "the role of ${ }^{201} \mathrm{Tl}$ myocardial perfusion scanning in evaluating postoperative graft status remains uncertain". In the original work of Ritchie et al..$^{13}$ only 11 out of the 20 patients who were examined had a complete preoperative scintigraphic evaluation including both exercise and resting images which are a prerequisite for the detection of postoperative changes in distribution of perfusion. And among the 27 patients studied by Greenberg and co-workers ${ }^{14}$ only nine patients were examined scintigraphically before surgery. Finally, Verani et al..$^{15}$ could not correlate the results obtained in their 23 patients with bypass graft patency as shown by coronary arteriography.

In the present study, thallium-201 exercise myocardial scintigrams before and after operation in a group of 54 patients were analysed semiquantitatively and compared with the postoperative clinical findings and the exercise electrocardiogram. In a subgroup of 35 patients postoperative scinti- graphic changes were compared with the changes in the vascular status.

\section{Methods}

Thallium-201 exercise myocardial scintigrams are carried out routinely in most of the patients suspected of having coronary artery disease in this institution. For this study 54 consecutive male patients who were to undergo coronary artery bypass surgery were selected for participation. Their ages ranged between 34 and 67 years (mean age $52 \pm 8$ (SD) years). All patients complained of typical stable or chronically progressive angina pectoris. Of the 54 patients, 27 had a history of previous myocardial infarction documented by typical electrocardiographic and serum enzyme changes. The preoperative scintigraphic evaluation took place $10 \pm 8$ weeks before operation, while the postoperative imaging study was performed on average $24 \pm 10$ weeks after operation. The patients were told not to take beta-blocking agents and digitalis at least during the five days preceding exercise scintigraphy; treatment with glyceryl trinitrate was continued to avoid severe anginal attacks. Thirtyfive patients were recatheterised after operation at the time when the second scintigram was performed, because of persistent or recurrent chest pain in 25 of them and a postoperative myocardial infarction in two. In the eight patients who were asymptomatic coronary arteriography was repeated because the surgeons as well as the patients themselves were interested in the success of the operation.

At preoperative coronary arteriography, seven patients $(13 \%)$ had single vessel disease, 17 patients $(31 \%)$ had double vessel disease, and 30 patients $(56 \%)$ had triple vessel disease. At operation, nine patients received a single bypass graft, and 26 received two bypass grafts; 16 patients had three bypass grafts, and three patients had four grafts. On average $2 \cdot 2$ bypass grafts were implanted per subject. In all instances saphenous vein homotransplants were used.

\section{THALLIUM-201 EXERCISE MYOCARDIAL SCINTIGRAPHY}

To perform myocardial imaging after exercise, the fasting patients were stressed on a bicycle ergometer in the upright position until the appearance of angina or of electrocardiographic abnormalities (see later) in the continuously recorded three lead electrocardiogram (V2/V4/V6), or until submaximal heart rate was achieved under steady state conditions. At this point $1.5 \mathrm{mCi}$ thallium-201 chloride (New England Nuclear Corp., North Billerica, Mass., USA) were injected intravenously and the 
patient was asked to continue exercising for another two minutes. He then lay down and five minutes after stopping the exercise, imaging was begun. Scintigrams were obtained in the $45^{\circ}$ and $60^{\circ}$ left anterior oblique, anterior, and left lateral positions by rotating the gamma camera head over the supine patient. Using a Picker Dyna Camera 4/12 (Picker Corp., Cleveland, Ohio, USA) with a parallel hole collimator peaked within the region of 69 to $83 \mathrm{KeV}$ 250000 count analogue images were recorded either on Polaroid prints or on CRT- $x$-ray film. Data accumulation was performed by means of a PDP-11 computer (Digital Equipment Corp., Maynard, Mass., USA) using the gamma-11 programme. The images were digitised on an Elscint-CTP-System (Elscint Ltd., Haifa, Israel), enhanced by a five-point smoothing procedure and displayed in a single frame of $96 \times 96$ matrix elements (zooming) in eight colours, with an additional colour to indicate overrange. This preset colour count range comprising in total either 32 or 64 counts per cell was set by adjusting the base of the colour count range such that only one single cell within the myocardial wall showed overrange activity. Thus, the relative activities within the cells overlying the different regions of the myocardial wall could be calculated by comparing the number of counts per cell as indicated by its colour to the number of counts of the cells with maximal activity, that is the cells the colour of which was second to the colour indicating overrange activity in the colour count range. Background activity was assumed to be constant. This has been shown to be feasible by the experimental work of Narahara and colleagues. ${ }^{16}$ The images were printed in full size on paper using a nine colour printer.

In a previous study ${ }^{17}$ we compared the range of the relative activities in the different regions of the myocardial wall in a group of normal subjects and in a group of patients with arteriographically proven coronary vascular lesions of more than 50 per cent reduction in lumen diameter. Neither in the exercise nor in the resting study did the differences in the relative activities within the different regions of the wall exceed 15 per cent in the normal group, whereas in all patients with coronary artery lesions the activity within the myocardial region supplied by this artery was less than 80 per cent of the maximal activity after the exercise test. Based on this observation a perfusion defect was defined as a transmural segment with a circumferential length at least equal to wall thickness showing less than 80 per cent of maximal thallium-201 activity (Fig. 1).

Four hours after the first scintigram, when redistribution had occurred, a second series of images was obtained in the same projections as during the

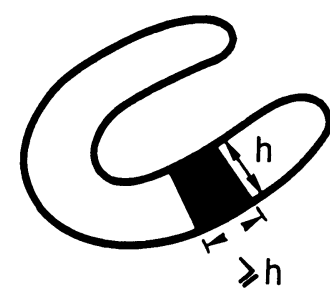

Fig. 1 Criteria for semiquantitative assessment of thallium-201 myocardial scintigrams. A perfusion defect was defined as a transmural segment with a circumferential length at least equal to wall thickness showing less than 80 per cent of maximal thallium-201 activity.

recording of the exercise images. These scintigrams then represented the thallium-201 distribution under resting conditions and by comparison with the exercise images one could differentiate between exercise-induced perfusion defects representing ischaemic regions and constant perfusion defects attributable to scarred tissue.

\section{CATHETERISATION AND CORONARY ARTERIOGRAPHY}

Pre- and postoperative cardiac catheterisation took place within three weeks after the exercise myocardial scintigraphy. After performing the left ventriculograms by biplane cineangiocardiography using $50 \mathrm{ml}$ of 76 per cent Urografin $\otimes$ injected into the left ventricular cavity, selective coronary arteriography by the Judkins technique was carried out in multiple projections. The arteriograms were interpreted by two independent observers who were unaware of the clinical findings and the outcome of the myocardial scintigraphy. A vascular narrowing of 70 per cent or more of the lumen diameter was considered to be significant. To assess quantitatively the status of coronary vascularisation before and after operation the coronary artery lesions as well as the bypass graft patency were scored according to the proposal of Levine et al. ${ }^{18}$ Thus, coronary artery narrowings of less than 70 per cent of lumen diameter as estimated from at least two different projections of the arteriogram were given the value 0 . A stenotic lesion of 70 to 90 per cent was assigned the value of -0.5 , and a lesion of more than 90 per cent narrowing the value $-1 \cdot 0$. In addition, a patent graft was assigned the value $+1 \cdot 0$ and an occluded graft the value 0 . Since all patients showed at least one significant coronary artery stenosis at preoperative arteriographic evaluation, the preoperative vascularisation index (VI) was always negative, averaging $-2 \cdot 4 \pm 1 \cdot 5$ (SD). According to this numerical construction, the 
degree of vascular obstruction is given by the negative vascularisation index of Levine $(-\mathrm{VI})$.

RESTING AND EXERCISE ELECTROCARDIOGRAM A normal 12 lead electrocardiogram at rest was recorded before operation in 35 of the 54 patients. One patient had a complete right bundle-branch block. In the remaining 18 patients the resting electrocardiogram showed the signs typical of either chronic anterior, inferior, or inferoposterior infarction, findings that corresponded to the history of previous myocardial infarction. In nine patients, however, the electrocardiogram recorded at the time of the preoperative scintigraphic evaluation disclosed no signs of chronic infarction despite welldocumented characteristic changes observed during the acute event.

Exercise testing was performed by supine multistage bicycle ergometry. During the entire procedure a three lead electrocardiogram (V2/V4/ V6) was continuously monitored and blood pressure taken repeatedly. The patients were stressed by stepwise increase in the workload until either chest pain or pathological electrocardiographic changes occurred or until age-predicted submaximal heart rate was achieved.

The exercise electrocardiogram was considered abnormal if a horizontal or downsloping ST segment depression occurred of more than $0.1 \mathrm{mV}$ below the baseline and lasting for more than $0.08 \mathrm{~s}$ beyond the $\mathrm{J}$ point during exercise or in recovery. The sudden appearance of multiple multifocal ventricular beats or of a new complete left bundlebranch block during the stress test was also considered to indicate myocardial perfusion abnormalities.

Preoperatively, the exercise electrocardiogram was abnormal in 36 of the 54 patients $(67 \%)$ and in one patient it could not be interpreted because of pre-existing complete right bundle-branch block. Thirty-three patients exhibited a typical ST segment depression and one patient with suspected anterior wall aneurysm showed a distinct elevation of the ST segment up to $0.6 \mathrm{mV}$ above the baseline. In one patient the exercise test had to be terminated abruptly after the sudden onset of salvos of multifocal ventricular beats, and in another patient a complete left bundle-branch block appeared during exercise. In 35 patients anginal pain, with or without pathological electrocardiographic changes, forced termination of the exercise stress test. This type of routine exercise stress test was performed on each patient several days before myocardial exercise scintigraphy. It served to determine the workload at which clinical symptoms and/or electrocardiographic changes occurred.

\section{STATISTICS}

All results were expressed as means \pm 1 SE. Paired and unpaired comparisons with Student's $t$ test were used to evaluate the statistical significance of differences in the data within and between groups. Proportions were analysed with either the test of McNemar (paired case) or the $x^{2}$ test (unpaired case) using Yates' correction if the sample sizes were small. ${ }^{10}$

\section{Results}

PRE- AND POSTOPERATIVE THALLIUM-201 SCINTIGRAMS

The preoperative exercise scintigrams of 51 of 54 patients showed typical, isolated zones of reduced thallium-201 uptake which filled in as redistribution occurred, thus indicating exercise-induced ischaemic regions. Moreover, in 25 of the 51 patients a second defect was identified, which persisted in the resting scintigram and thus was interpreted as representing scarred tissue. In two of the 54 patients ischaemic regions adjacent to a zone of infarction were suspected since the large perfusion defect observed after exercise was much reduced in size at rest. And finally, one of the 54 patients showed a diffuse scintigraphic pattern after exercise as well as at rest, with several spots of reduced thallium-201 uptake in different regions of the wall, suggesting diffuse myocardial disease.

Thus, exercise-induced transitory defects as evidence for stress-dependent ischaemia were unequivocally observed in 51 of the 54 patients indicating a 94 per cent sensitivity of thallium-201 exercise scintigraphy for detecting ischaemic regions in this small and highly selected group of patients. This was significantly $(p<0.001)$ higher than the 67 per cent sensitivity of the exercise electrocardiogram which was abnormal in only 36 of the 54 patients. Constant perfusion defects caused by scarred tissue were found in 25 of the 27 patients with a previous myocardial infarction proven by electrocardiogram and serum enzyme changes, resulting in a sensitivity of 93 per cent to detect myocardial infarction; this again was higher than the 67 per cent sensitivity of the electrocardiogram at rest $(p<0.05)$ (abnormal $Q$ waves or loss of $R$ wave potential in 18 of the 27 patients).

With respect to the dominant coronary lesion the scintigraphic findings corresponded closely to the results of coronary arteriography. In the seven cases with single vessel disease the vascular lesion was precisely predicted on the basis of the scintigraphic defect, whereas in the 47 cases with double or triple vessel disease multiple stenotic lesions were suspected in only 20 of them. 
The postoperative scintigrams were examined in two steps. First they were analysed for perfusion defects (their location and size) as they occurred either in the exercise study alone or in both the exercise and resting scintigram. Secondly, the postoperative scintigrams were compared with the preoperative studies. Since the purpose of the investigation was to evaluate thallium-201 scintigraphy for its usefulness in assessing the success of coronary artery bypass surgery, the patients were classified into three groups according to the results of the postoperative scintigraphy. Group 1 comprised 31 patients in whom the preoperatively visible perfusion defects after exercise were abolished postoperatively, that is thallium-201 activity remained within normal limits (above $80 \%$ of maximal activity) in all regions of the myocardial wall except for constant perfusion defects caused by a preoperative myocardial infarction, which were seen in both studies in 19 patients. Group 2 comprised 16 patients in whom the postoperative scintigrams were identical to the preoperative ones, that is similar exercise-induced perfusion defects of identical location and size were visible in both studies. In six of these patients the preoperatively diagnosed myocardial infarction was identified postoperatively as well. Finally, group 3 comprised seven patients in whom the preoperatively observed exercise-induced perfusion defects were either more pronounced and increased in size postoperatively or additional new perfusion defects were noted. Two of the seven patients suffered a myocardial infarction which occurred postoperatively.

The relative pre- and postoperative thallium-201 activities within the preoperatively ischaemic region are shown in Fig. 2. In group 1 the relative thallium201 activity averaged $70 \pm 3$ per cent (means \pm 1 SEM) after exercise and $85 \pm 3$ per cent at rest preoperatively $(\mathrm{p}<0.001)$. Postoperatively, the relative thallium-201 activity within the same region amounted to $88 \pm 2$ per cent after exercise and $93 \pm 2$ per cent at rest (NS). The pre- and postoperative values after exercise differed significantly at the $\mathrm{p}<0.001$ level, while the pre- and postoperative values at rest were also different at the $\mathrm{p}<0.02$ level, indicating severe hypoperfusion preoperatively, which resulted in incomplete redistribution within the four hours between the exercise and the resting study. In group 2 the respective values were $75 \pm 2$ per cent after exercise and $84 \pm 2$ per cent at rest preoperatively $(p<0.001)$ and $74 \pm 3$ per cent after exercise and $84 \pm 2$ per cent at rest postoperatively $(p<0.001)$. No significant difference existed between the pre- and postoperative values either after exercise or at rest. In group 3

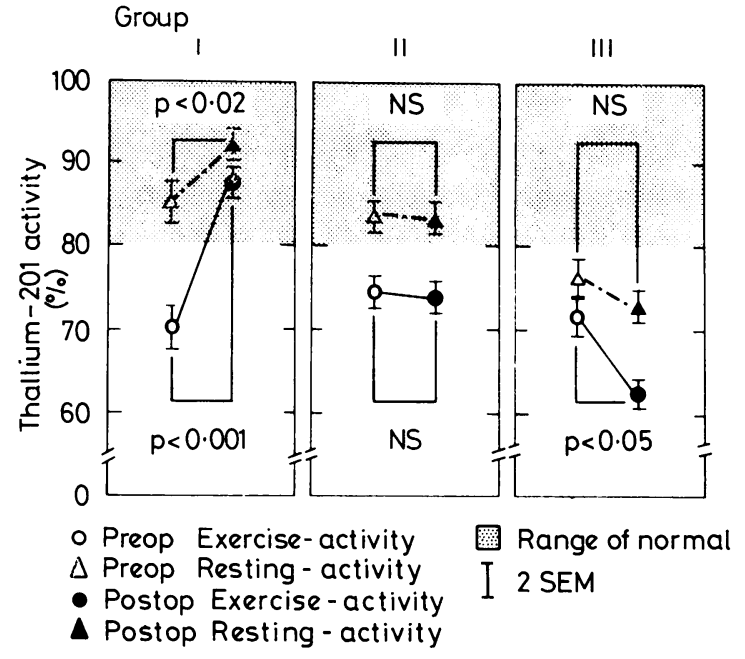

Fig. 2 Pre- and postoperative thallium-201 activity within the ischaemic region after exercise and at rest relative to maximal myocardial thallium activity. The shaded region indicates the range of normal. Expressed are means \pm 1 SEM. In group 1, comprising 31 patients, thallium activity within the dominant ischaemic region was depressed after exercise preoperatively and was within normal limits postoperatively. The significant increase in thallium activity at rest postoperatively indicates increased resting perfusion. In group 2, comprising 16 patients, thallium activity after exercise was diminished preoperatively and remained diminished postoperatively, whereas in group 3, comprising seven patients, both the thallium activity after exercise and at rest were reduced preoperatively and were found to be even more reduced postoperatively.

the figures were $72 \pm 2$ per cent after exercise and $76 \pm 4$ per cent at rest preoperatively (NS) and $63 \pm 2$ per cent after exercise and $71 \pm 3$ per cent at rest postoperatively $(p<0.05)$. The pre- and postoperative values after exercise differed significantly at the $p<0.05$ level whereas no significant difference was observed between the respective values at rest.

In Fig. 3 the digitised scintigram in the LAO $45^{\circ}$ position after exercise and at rest-before and after operation-of a patient in group 1 is shown. This patient who had triple vessel disease received four bypass grafts which were all patent at restudy. Apart from some slight thoracic discomfort not related to physical activity and presumably a result of sternotomy, the patient was symptom free after operation, whereas before it he had complained of severe angina. The large preoperative perfusion defect seen in the anteroseptal wall after exercise, which was related to the predominant lesion in the proximal left anterior descending coronary artery, had completely disappeared after operation. 


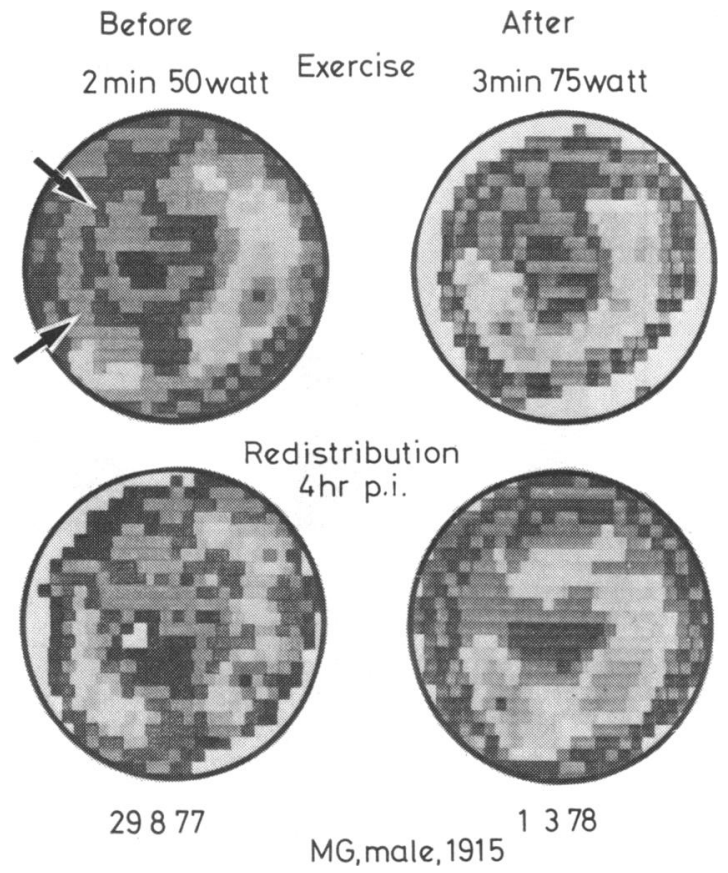

Fig. 3 Digitised scintigram in the LAO $45^{\circ}$ position after exercise and at rest-before and after operationof a 63-year-old patient in group 1 with three vessel disease. $A$ large perfusion defect in the anteroseptal wall (indicated by the arrows) was found preoperatively after exercise which filled in as redistribution occurred. This defect was related to a severe proximal lesion of the left anterior descending coronary artery. At operation the patient received four bypass grafts which were all patent at restudy. Correspondingly, the postoperative thallium scintigram disclosed normal perfusion after exercise as well as at rest in all segments of the myocardial wall.

THALIIUM-201 SCINTIGRAM AND CLINICAL AND ELECTROCARDIOGRAPHIC FINDINGS AFTER OPERATION

As summarised in Fig. 4, the clinical symptoms, that is chest pain at rest or during physical stress, and the exercise electrocardiogram correlated poorly with the scintigraphic findings. Of the 54 patients, 22 were symptom free after operation. However, two of them showed a pathological electrocardiographic response during exercise even though no perfusion defect was found in the scintigram and the postoperative arteriographic evaluation showed complete revascularisation. In eight of the 20 patients who were symptom free and had normal exercise electrocardiograms postoperative and myocardial perfusion was unchanged as compared with the preoperative evaluation. The postoperative arteriography performed in six of these patients indicated a severe progression of the atherosclerotic disease in the native coronaries and occlusion of seven of 15 bypass grafts.

No perfusion defects could be detected in the postoperative scintigrams of 11 patients with postoperative chest pain but who had a normal exercise electrocardiogram. Nine of the 11 patients were also restudied arteriographically. In all but one patient a significant improvement in the vascularisation status was noted and only one of the 18 bypass grafts was occluded. In one patient with multiple severe vascular lesions, however, both implanted bypass grafts were occluded and a progression in severity of the lesions as well as new narrowings were found at restudy. The scintigram which, in retrospect, was found to be falsely negative should be reinterpreted as resulting from a balance of diminished perfusion in all

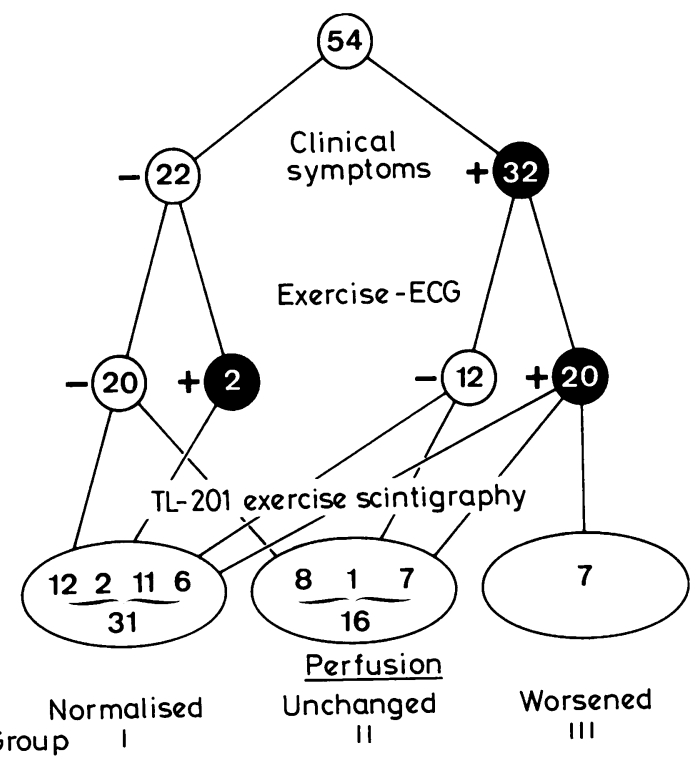

Fig. 4 Comparison of postoperative clinical symptoms and exercise electrocardiogram in relation to thallium-201 exercise scintigraphy. Postoperatively, 22/54 patients were symptom free whereas $32 / 54$ patients still complained of chest pain. In two of the 22 asymptomatic patients the exercise electrocardiogram was abnormal. Both patients, however, showed normal perfusion within the preoperatively ischaemic region in the thallium scintigram. In eight of 20 asymptomatic patients with normal exercise electrocardiogram the scintigram showed identical perfusion defects before and after operation. In contrast, improvement in perfusion was documented in 11/12 symptomatic patients with normal exercise electrocardiogram and in six of 20 patients who complained of chest pain afterioperation in whom the exercise electrocardiogram was abnormal. 
vascular beds leading to an overall reduction of thallium uptake even during exercise.

Only two of the six patients who had chest pain and a pathological exercise electrocardiogram, but who showed a normal thallium-201 scintigram postoperatively, could be restudied by coronary arteriography. In the first patient all three, and in the second patient two out of three bypass grafts were patent and showed good anterograde flow.

Among the six out of the seven patients with pronounced or new postoperative perfusion defects who were recatheterised all grafts were occluded or severely stenotic except for that in one patient in whom the two implanted bypass grafts were patent but who had sustained a large anteroseptal infarction postoperatively caused by occlusion of the left anterior descending coronary artery just distal to the site of graft implantation.

To summarise these findings, thallium-201 scintigraphy disclosed unchanged postoperative myocardial perfusion, corroborated by arteriography, in 40 per cent $(8 / 20)$ of those patients who had no clinical symptoms and normal postoperative exercise electrocardiograms. Without scintigraphy these patients would have been falsely classified as being operation successes. In contrast, a failure of the surgical intervention could be excluded by the postoperative scintigram which had returned to normal in 17 of the 31 patients $(53 \%)$ in whom deterioration of the myocardial perfusion status was suspected from the complaints of chest pain with or without a pathological exercise electrocardiogram.

\section{THALLIUM-201 SCINTIGRAM AND}

\section{ARTERIOGRAPHIC FINDINGS}

The bypass graft patency rate paralleled the scintigraphic findings in the 35 patients who underwent an arteriographic restudy. It amounted to 81 per cent (29/36 grafts) in group 1 (16 patients restudied) which differed significantly $(p<0.001)$ from group 2 (13 patients restudied) where it amounted to 38 per cent (13/34), whereas it was only 15 per cent (2/13) in group 3 (six patients restudied) (Fig. 5).

The changes in myocardial perfusion after operation, however, depend not only upon bypass graft patency but also on the course of the atherosclerotic disease in the native vessels. Thus, it seemed appropriate to consider both the vascular lesions and the bypass graft patency, and to establish the degree of obstruction as defined by the negative value of the vascularisation index proposed by Levine et al. ${ }^{18}$ The overall degree of vascular obstruction declined in group 1 from $2 \cdot 1$ \pm 0.3 preoperatively to $1 \cdot 1 \pm 0.3$ postoperatively $(\mathrm{p}<0.001)$, while it remained unchanged in

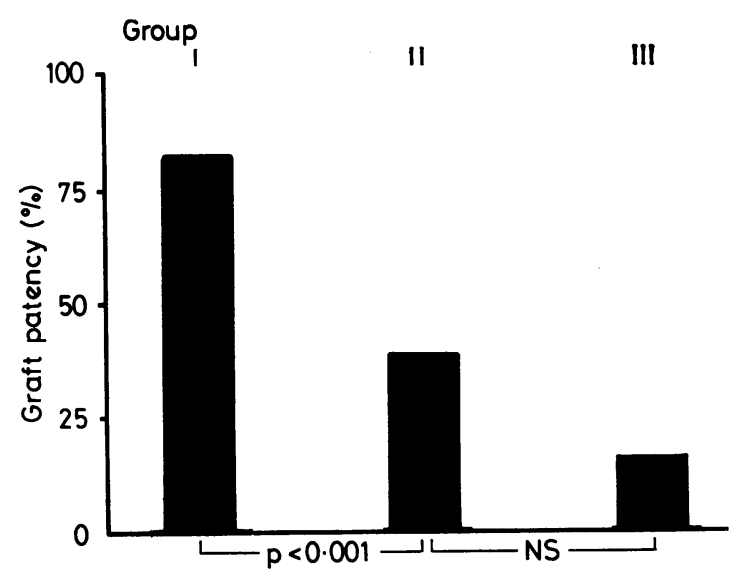

Grafts open

$$
30 / 36
$$

$13 / 34$

$2 / 13$

Fig. 5 The aortocoronary bypass graft patency rate assessed in 35 out of the 54 patients by selective coronary arteriography paralleled the scintigraphic findings. It amounted to 81 per cent (30/36 grafts patent) in 16 . arteriographically restudied patients out of the 31 patients who belonged to group 1 (normalised perfusion postoperatively according to the thallium scintigram). In group 2 (unchanged postoperative perfusion scintigraphically) bypass patency rate was significantly less, amounting to 38 per cent (13/34 grafts patent) in 13 of the 16 patients assigned to this group who were recatheterised. And in group 3 (worsened postoperative perfusion according to the thallium scintigram) it amounted to only 15 per cent (two of 13 grafts patent) in six out of seven patients who were restudied arteriographically in this group.

group 2, averaging $3.0 \pm 0.4$ and $3 \cdot 1 \pm 0.5$ (NS), respectively. In group 3 it even tended to increase from $2.2 \pm 0.6$ preoperatively to $3.3 \pm 0.6$ (NS) postoperatively (Fig. 6).

Further confirmation that the results of the postoperative thallium-201 scintigraphy are intimately linked to the overall vascular status was obtained when the 35 patients with postoperative arteriography were analysed separately according to the change in their vascular obstruction index (Table). In four patients complete revascularisation (postoperative vascular obstruction index zero) was achieved by the surgical intervention. Correspondingly, thallium-201 activity after exercise within the previously ischaemic region had increased to normal. Classified according to their postoperative thallium-201 scintigram all four patients belonged to group 1 . Seventeen patients showed a decrease in the obstruction index, that is an improvement in their vascularisation status after operation even though some impairment remained. The postoperative thallium-201 activity after exercise within the preoperatively ischaemic region 
was found to be within normal limits $(83 \pm 3 \%$ as compared with $72 \pm 3 \%$ preoperatively, $\mathrm{p}<0.025$ ). Of the 17 patients, 11 were classified according to their postoperative thallium-201 scintigram in group 1 , whereas five patients belonged to group 2 , and one even to group 3; this latter patient had

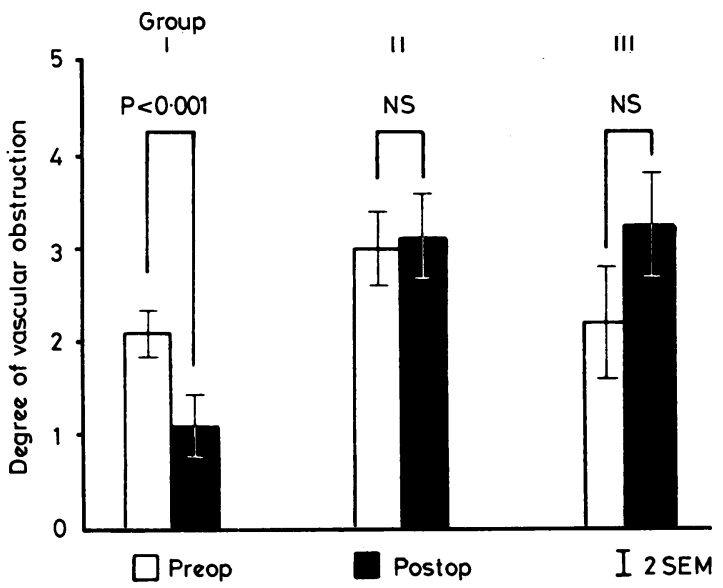

Fig. 6 In order to establish the overall status of vascularisation before and after operation a numerical construct including all vascular lesions as well as bypass graft patency was performed similar to the one proposed by Levine et al. ${ }^{18}$ in the 35 patients who underwent a postoperative arteriographic evaluation (for further explanation see text). Whereas in group 1 (normalised perfusion postoperatively according to the thallium scintigram), the degree of vascular obstruction was significantly reduced postoperatively, it remained unchanged in group 2 (unchanged postoperative perfusion scintigraphically), and even tended to be increased in group 3 (worsened postoperative perfusion). received two bypass grafts at operation which were found to be patent at restudy, and after operation, however, he had a large anteroseptal infarction caused by occlusion of the left anterior descending coronary artery just distal to the site of graft implantation, which led to a new perfusion defect in the postoperative scintigram.

In eight patients the vascularisation state remained unchanged after operation, as was the thallium-201 uptake after exercise within the predominant ischaemic region. Six of these eight patients had been assigned to group 2, according to the postoperative thallium-201 scintigram, and two patients to group 3.

In six patients, finally, the vascular situation was found to have deteriorated postoperatively because of bypass occlusion, the appearance of new vascular lesions, or progression of pre-existing narrowings of ungrafted vessels. Thallium-201 uptake within the predominant ischaemic region tended to be less after operation than before. Two of the six patients had been assigned to group 2 according to their postoperative thallium-201 scintigram, three patients to group 3, and one patient to group 1 ; this patient had multiple vascular lesions and both bypass grafts were found to be occluded at restudy, resulting in an inhomogeneous postoperative thallium-201 scintigram without a distinct region of diminished thallium-201 uptake to meet the criterion of a true perfusion defect.

In summary, then, a correct prediction of the state of vascularisation by thallium-201 scintigraphy was achieved in 80 per cent of the patients of this subgroup (28/35: four patients with no obstruction and 11 patients with decreased obstruction had been

Table Pre- and postoperative thallium-201 exercise scintigrams in 35 patients according to postoperative change in vascular status assessed by vascular obstruction index

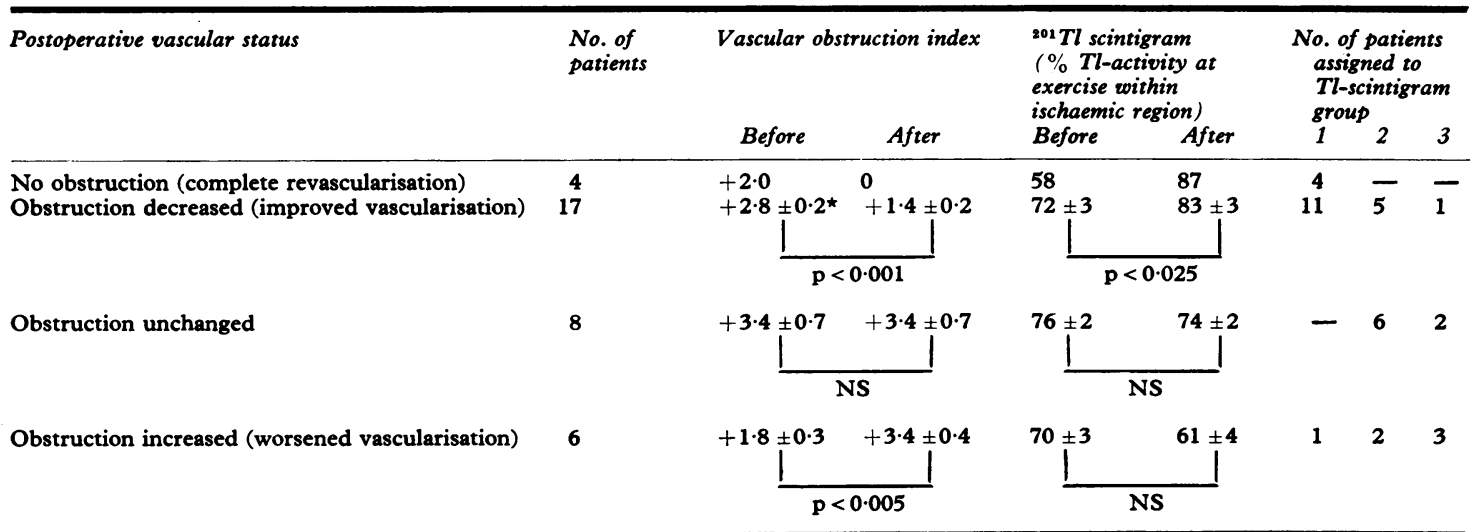

$\star_{\text {Mean }} \pm 1$ SEM. 
correctly assigned to group 1; from the eight patients with unchanged obstruction, six had been assigned to group 2, and two to group 3; and from the six patients with increased obstruction, two had been assigned to group 2 and three to group 3 ). On the other hand, the scintigraphic results did not compare with the arteriographic findings in 20 per cent (7/35: from the 17 patients with decreased obstruction, five had been assigned to group 2 and one even to group 3, and one patient with increased obstruction had been falsely assigned to group 1).

\section{Discussion}

The widespread use of coronary artery bypass surgery in the care of patients with coronary heart disease means that methods for evaluating its effect on regional myocardial perfusion are most desirable. Coronary arteriography is definitely the most direct approach to visualise bypass graft patency. Its invasive character combined with a certain risk for the patient, however, prohibits serial studies.

The clinical findings alone, even if combined with exercise testing and the recordings of the exercise electrocardiogram, may, at best, provide a rough guide in assessing the postoperative situation but clearly do not allow precise evaluation of the surgical treatment.

Thus, radionuclide techniques because they are noninvasive and readily available have been suggested as useful methods of determining the effect of coronary revascularisation procedures. Gated radionuclide cineangiography allows assessment of left ventricular ejection fraction and regional contraction not only at rest but also during exercise. ${ }^{20} 21$ The accuracy of the method during exercise, however, needs further validation by comparison with contrast angiography. In contrast to this technique which aims to detect functional abnormalities myocardial scintigraphy allows disturbances in regional myocardial perfusion to be seen. Among the different isotopes available for this purpose thallium-201 has been shown to be best suited for myocardial imaging since it has the most favourable physical and biological properties. $^{22}{ }^{23}$

Indeed, the results obtained from postoperative thallium-201 exercise myocardial scintigraphy in other studies ${ }^{13} 1424$ suggest the usefulness of the method if they are compared with the findings of postoperative coronary arteriography. Some criticism is, however, appropriate since thallium-201 scintigrams are most often interpreted by visual analysis of the analogue images only, and are thus dependent upon the experience of the examiner. Furthermore, the interpretation of the postoperative scintigram is more difficult than that of the preoperative one because the improvement of flow to previously ischaemic regions may result in complex changes in the thallium distribution pattern especially if more than one bypass graft has been implanted. In addition, the surgical procedure by itself may lead to alterations in the scintigraphic appearance of the heart. To draw definite conclusions about the status of vascularisation it seems mandatory to compare carefully the postoperative and preoperative scintigrams.

The results of the present study show that by applying a semiquantitative criterion to the scintigrams and by careful comparison of the pre- and postoperative images, thallium-201 scintigraphy is a reliable and useful method of assessing the success of coronary artery bypass surgery. Thus, a correct prediction of either complete or at least improved vascularisation was achieved by scintigraphy in 15 out of $16(94 \%)$ patients classified in group 1 (Table). The postoperatively unchanged or even worsened thallium scintigrams found in 19 of the 35 patients corresponded in 13 of them $(68 \%)$ with the unchanged or worsened vascular situation detected arteriographically after operation. In the remaining six patients with unchanged or worsened thallium scintigrams after operation the vascularisation was improved. In fact, it could not be determined, except by thallium scintigraphy, whether perfusion really had been altered postoperatively in these patients, since no complete vascularisation resulted from the surgical intervention and six of the 16 implanted bypass grafts were found to be occluded.

As compared with the postoperative exercise electrocardiogram the postoperative thallium scintigrams were of greater diagnostic accuracy. Whereas in only one out of the $16(6 \%)$ patients who had a normal postoperative thallium scintigram (group 1 in the Table) did the preoperative scintigram have to be reassessed after arteriography as having been falsely normal, the postoperative exercise electrocardiograms were pathological in four patients $(25 \%)$. On the other hand, the postoperative exercise electrocardiograms were pathological in only eight of the 13 patients $(62 \%)$ with a postoperative unchanged or even worsened thallium scintigram and an arteriographically proven unchanged or deteriorating vascular situation.

In respect of clinical symptoms, all except one of the 16 patients with normal postoperative thallium scintigrams indicating better or complete vascularisation had improved. But only eight of them (50\%), however, were totally symptomless, the remainder still having some chest pain. In contrast, of the 13 patients with postoperatively unchanged or wor- 
sened myocardial perfusion and unchanged or deteriorating vascularisation, two were entirely symptom free and five patients had clearly improved.

In conclusion, the clear relation between the changes in perfusion after operation as assessed scintigraphically and the bypass graft patency rate and degree of vascularisation, respectively, show that thallium-201 exercise scintigraphy is a useful and reliable method for documenting the success of this intervention. Scintigraphy is superior to the clinical evaluation of the patients and to the standard routine examination such as the exercise electrocardiogram. Though any prediction of bypass graft closure has to be made with caution since a postoperatively identical or even deteriorated perfusion may result from progression of the disease in the native vessels as well, the method helps to determine with good precision whether postoperative arteriographic re-evaluation is necessary. Moreover, the method is suitable for long-term follow-up of patients who have undergone coronary artery bypass surgery. Finally, combination of scintigraphy with other radionuclide techniques capable of assessing left ventricular function and regional wall motion may even further increase the sensitivity and specificity of this kind of approach and broaden knowledge of overall cardiac function in these patients.

\section{References}

'Hurst JW, King SB III, Logue RB, et al. Value of coronary bypass surgery. Am $f$ Cardiol 1978; 42: 308-29.

${ }^{2}$ McIntosh HD, Garcia JA. The first decade of aortocoronary bypass grafting, 1967-1977. Circulation 1978; 57: 405-31.

${ }^{3}$ Favaloro RG. Direct myocardial revascularization: a ten year journey. Am $\mathcal{f}$ Cardiol 1979; 43: 109-29.

${ }^{4}$ Kouchoukos NT, Kirklin JW, Oberman A. An appraisal of coronary bypass grafting. Circulation 1974; 50: 11-6.

${ }^{5}$ Shepherd RL, Itscoitz SB, Glancy DL, et al. Deterioration of myocardial function following aorto-coronary bypass operation. Circulation 1974; 49: 467-75.

'Benchimol A, Dos Santos A, Desser KB. Relief of angina pectoris in patients with occluded coronary bypass grafts. Am $\mathcal{F}$ Med 1976; 60: 339-43.

'Di Luzio VD, Roy PR, Sowton E. Angina in patients with occluded aorto-coronary vein grafts. $B r$ Heart $\mathcal{F}$ 1974 ; 36: $139-47$.

${ }^{8}$ Achuff SC, Griffith LSC, Conti CR, et al. The 'angina-producing' myocardial segment. An approach to the interpretation of results of coronary bypass surgery. Am $₹$ Cardiol 1975; 36: 723-33.

${ }^{8}$ Zaret BL, Martin ND, McGowan RL, Strauss HW, Wells HP Jr, Flamm MD Jr. Rest and exercise potassium-43 myocardial perfusion imaging for the non-invasive evaluation of aorto-coronary bypass surgery. Circulation $1974 ; 49$ : 688-95.
${ }^{10}$ Lurie AJ, Salel AF, Berman DS, Denardo GL, Hurley EJ, Mason DT. Determination of improved myocardial perfusion after aorto-coronary bypass surgery by exercise rubidium-81 scintigraphy. Circulation 1976; 53 and 54: Suppl III : 20-3.

${ }^{11}$ Degeorges M, Roucayrol JC, Dupérier C, Butez J, Comet $\mathrm{M}$, Sol Ch. La scintigraphie du myocarde après injection de thallium 201 au cours d'une épreuve d'effort. Arch Mal Coeur 1976; 69: 883-9.

${ }^{12}$ Rosenblatt A, Lowenstein JM, Kerth W, Handmaker H. Post-exercise thallium-201 myocardial scanning: a clinical appraisal. Am Heart $\mathcal{f} 1977$; 94: 463-70.

${ }^{13}$ Ritchie JL, Narahara KA, Trobaugh GB, Williams DL, Hamilton GW. Thallium-201 myocardial imaging before and after coronary revascularization. Circulation 1977 ; 56 : 830-6.

${ }^{14}$ Greenberg BH, Hart R, Botvinick EH, et al. Thallium201 myocardial perfusion scintigraphy to evaluate patients after coronary bypass surgery. Am $\mathcal{f}$ Cardiol 1978; 42: 167-76.

${ }^{15}$ Verani MS, Marcus ML, Spoto G, Rossi NP, Ehrhardt JC, Razzak MA. Thallium-201 myocardial perfusion scintigrams in the evaluation of aorto-coronary saphenous bypass surgery. $¥ \mathrm{Nucl}$ Med 1978; 19: 765-72.

${ }^{16}$ Narahara KA, Hamilton GW, Williams DL, Gould KL. Myocardial imaging with thallium-201: an experimental model for analysis of the true myocardial and background image components. $\mathcal{F}$ Nucl Med 1977; 18: $781-6$.

${ }^{17}$ Luetolf UM, Schneider E, Glanzmann $\mathrm{CH}$, et al. Zur Methodik der Myokardszintigraphie mit Thallium201: Grenzen zum Pathologischen. Schweiz Med Wochenschr 1977; 107: 1574-7.

${ }^{18}$ Levine JA, Bechtel DJ, Cohn PF, et al. Ventricular function before and after direct revascularization surgery. Circulation 1975; 51: 1071-8.

${ }^{19}$ Armitage P. Statistical methods in medical research. New York: John Wiley, 1973.

${ }^{20} \mathrm{Kent} \mathrm{KM}$, Borer JS, Green MV, et al. Effects of coronary-artery bypass on global and regional left ventricular function during exercise. $N \mathrm{Engl} f \mathrm{Med}$ 1978; 298: 1434-9.

${ }^{21}$ Borer JS, Bacharach SL, Green MV, Kent KM, Johnston GS, Epstein SE. Effect of nitroglycerin on exercise-induced abnormalities of left ventricular regional function and ejection fraction in coronary artery disease. Circulation 1978; 57: 314-20.

${ }^{22}$ Bradley-Moore PR, Lebowitz E, Greene MW, Atkins HL, Ansari AN. Thallium-201 for medical use. II : Biologic behavior. $\mathcal{F}$ Nucl Med 1975; 16: 156-60. ${ }^{23}$ Strauss HW, Harrison K, Langan JK, Lebowitz E, Pitt B. Thallium-201 for myocardial imaging. Relation of thallium-201 to regional myocardial perfusion. Circulation 1975; 51 : 641-5.

${ }^{24}$ Kostuk WJ, Deatrich D, Chamberlain MJ. Noninvasive assessment of patients following aortocoronary bypass surgery. Can $\mathcal{F}$ Surg 1978; 21: 104-6.

Requests for reprints to Dr Heinz O Hirzel, Division of Cardiology, Medical Policlinic, Department of Internal Medicine, University Hospital, CH-8091 Zurich, Switzerland. 